\title{
FILOSOFÍA E IDEOLOGÍA DE LAS TEORÍAS DE LA PENA*
}

\author{
ENRIQUE BACIGALUPO \\ Catedrático de Derecho Penal \\ Magistrado del Tribunal Supremo de España
}

\begin{abstract}
RESUMEN: El autor de este artículo nos presenta de manera sumaria -desde las ideologías de la pena- el apogeo, desarrollo y la crisis que la sanción penal ha sufrido como corolario de un proceso continuo de degradación de las garantías fundamentales del derecho penal, y cuyo efecto más evidente ha implicado el asentamiento de paradojas complejas de resolver para el sistema de derecho penal, a saber, la intensa intervención penal en desmedro del concepto de persona asociándolo a una fuente de peligros. A esto se suma una espacio público-político surcado por los cantos de sirena de la seguridad y el punitivismo dejando en entredicho el fin primordial del derecho penal: definir y asegurar la libertad de la persona.
\end{abstract}

Palabras clave: Teoría de la pena, ideología, derecho penal moderno, derecho penal del enemigo.

ABSTRACT: The author of this article summarily presents us -from the ideologies of the penaltythe apogee, development and the crisis that the criminal sanction has suffered as a corollary of an ongoing process of degradation of the fundamental guarantees of criminal law, and whose most obvious effect has involved the settlement of paradoxes that are complex to resolve for the criminal law system, namely, the intense criminal intervention at the expense of the concept of person, associating it to a source of dangers. To this is added a public-political space furrowed by the siren songs of security and punitivism, leaving into question the primary purpose of criminal law: to define and ensure the freedom of the person.

Key words: Theory of penalty, ideology, modern criminal law, criminal law of the enemy.

1.

La filosofía o la ideología de las teorías de la pena es, desde el punto de vista de la presente exposición, el conjunto de ideas que tienen la pretensión de legitimar una determinada limitación de la libertad mediante ejercicio del ius puniendi en un Estado de Derecho. Tales ideas presuponen, por un lado, una concepción de la criminalidad dentro de un orden social determinado y, por otro, una noción de la reacción contra ella por medio de la privación de derechos del autor del delito, es decir, por medio de la pena u otras medidas del derecho penal, a través de los cuales el Estado está autorizado a restringir la libertad de los ciudadanos para garantizar los derechos a todos y cada uno.

En el marco constitucional del Estado de Derecho democrático actual las teorías de la pena expresan la función del derecho penal en una sociedad basada en la libertad, la igualdad y la dignidad de la persona. En este sentido es indudable que las teorías de la pena son también la expresión de una ideología. Pero, en todo caso, no pretenden enmascarar la realidad, sino revelarla.

\footnotetext{
* Agradecemos al profesor Jaime Gallegos quien ha facilitado este artículo para la presente edición de Derecho y Humanidades.
} 
La ideología del derecho penal, en consecuencia, es una ideología de la libertad, como lo son también otras concepciones del mundo, como, por ejemplo, el libre comercio o el colectivismo, la economía dirigida o la función social de la propiedad en el ámbito de la economía, que también comportan límites más o menos amplios de la libertad en la actividad humana. Sería erróneo creer que de esta manera solo se explica la pena privativa de la libertad, pues también la pena de multa y la de inhabilitación implican limitaciones (indirectas) de la libertad de acción.

Esta visión de la ideología del derecho penal presupone la aceptación de la legitimidad del Estado democrático de derecho establecido en las Constituciones democráticas modernas. En este punto la posición aquí presentada difiere claramente de otras visiones ideológicas que pudieran cuestionar ese marco y presuponen ya inicialmente la ilegitimidad del derecho penal, al entenderlo como un instrumento de la dominación de una clase sobre otra ${ }^{1}$.

Un auténtico discurso ideológico del derecho penal, en el sentido señalado, existió probablemente siempre, Protágoras, Sófocles, Aristóteles, Platón y Séneca son ejemplos del mundo antiguo ${ }^{2}$ y demuestran la persistencia histórica del problema.

El presente estudio se limita, sin embargo, al discurso ideológico del derecho penal moderno, que tiene su inicio en el siglo XVIII. Este derecho penal moderno, es decir el posterior a la Revolución Francesa, fue edificado sobre los principios que había expuesto en 1764 Beccaria $^{3}$ y se basó, por lo tanto, en una ideología racionalista elaborada por la filosofía del iluminismo. La limitación de la libertad por medio de la pena solo se entendía justificada como un medio para alcanzar una determinada meta socialmente valiosa. "El fin de la pena", escribía Beccaria, "no es otro que impedir al reo hacer nuevos daños a sus conciudadanos y motivar a los demás a no hacerlos de la misma manera”. Es a partir de esta idea que el art. 5 de la Declaration des droits de l'homme et du citoyen de 26 de agosto de 1789 estableció que "La loi n'a le droit de deféndre que les actions nuisables à la societê" y el art. 8 insistió en que "La loi ne doit establir que des peines strictement et evidentement nécessaires”. Ambas consignas generaron las cuestiones cuyas respuestas son la materia de la ideología del derecho penal moderno: En primer término: ¿qué es lesivo para la sociedad? Y en segundo lugar: ¿para qué debían ser evidentemente necesarias las penas?

La primera pregunta se refiere a qué conductas pueden ser objeto del derecho penal. La respuesta a ella tiene lugar en la parte especial del derecho penal, que contiene el catálogo de las acciones prohibidas y de las omisiones punibles. La parte especial del derecho penal es el marco en el que una sociedad define los límites de la libertad estableciendo qué acciones estima el legislador como dañinas para la sociedad en el sentido del art. 5 de la Declara-

\footnotetext{
${ }^{1}$ Confr. L. Gracia Martín, Luis. Prolegómenos para la lucha por la modernización y expansión del Derecho penal y para la crítica del discurso de resistencia. Valencia: Editorial Tirant lo Blanch, 2003; que considera que las garantías penales para las clases sometidas "funcionan como instrumentos de clasificación, disciplina y represión" (p. 181) y considera que actualmente es necesario un nuevo derecho penal cuyos contenidos deben ser "los comportamientos criminales de la clase poderosa y para la defensa de las demás clases sociales frente a semejante criminalidad” (p. 217).

${ }^{2}$ Confr. Hippel Robert. v., Deutsches Strafrecht I, 1925, pp. 461 y ss.

${ }^{3}$ Dei deltti e delle pene, 1764, Capítulo XV (edición de PISAPIA G. D., 1973, que concuerda con el orden de los capítulos aprobado por el propio Beccaria de la edición de 1774 de la Società dei Filosofi, fechada en Londres y que contiene los comentarios de Voltaire).
} 
ción de Derechos. La parte especial del derecho penal marca, en este sentido, el límite de la libertad en una sociedad. Los reclamos de un derecho penal mínimo o de reducción de la criminalización en ciertos ámbitos mediante discursos antidemagógicos frente a las tendencias expansivas de los legisladores ${ }^{4}$, las tesis que pretenden reducir el derecho penal exclusivamente a la lesión de bienes jurídicos ${ }^{5}$, las que, por el contrario, afirman que el objeto de protección es el sistema de una sociedad libre ${ }^{6}$ o las que, en el siglo XIX,

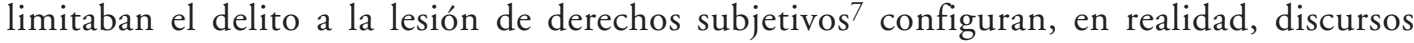
tendentes a establecer un determinado ámbito de libertad o, dicho en sentido inverso, los límites del Estado democrático frente al derecho natural (para utilizar la terminología del art. 4 de la Declaración de 1789) de la libertad.

La segunda cuestión planteada se refiere a la pena evidentemente necesaria, en el sentido del art. 8 de la Declaración de Derechos. Concretamente: ¿necesarias para qué? Las respuestas a esta pregunta pretende aclarar hasta dónde y en qué condiciones el Estado está autorizado a reprimir a quienes vulneran los límites de la libertad mediante comportamientos socialmente dañosos previstos en la ley penal.

No es posible tratar en el reducido espacio de esta lección ambas cuestiones. Concentraré la exposición en la ideología de la pena. La pregunta que debe ser respondida, entonces, es: ¿qué puede hacer legítimamente el Estado con el autor de un delito?

Ya en el siglo XVII se elaboró un primer discurso del derecho penal en este sentido, que se llevaría luego a la práctica en el Estado moderno. La premisa básica del mismo consistió en excluir de la potestad del Estado la venganza. Por lo tanto, se hizo necesario diferenciar conceptualmente la pena de la venganza. La venganza correspondía al estado

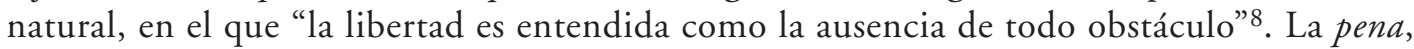
por el contrario, es considerada como una institución del Estado, es decir, del Derecho de una sociedad en la que "el individuo tiene derechos solo en tanto él reconozca los derechos de los otros" 9 . Por lo tanto, solo una pena orientada a un fin legítimo, se estimó, podría ser diferenciada de la venganza y considerada una legítima limitación de la libertad ${ }^{10}$. El

\footnotetext{
${ }^{4}$ Confr. Baratta A., en Dei Delitti e delle Pene, 2/1985, pp. 247 y ss.; del mismo: en Dei Deltti e delle Pene, 3/1985, pp. 413 y ss.

5 Confr. por todos Roxin C. Strafrecht, I -3a edición-, 1997, pp. 11 y ss.

${ }^{6}$ Confr. Amelung K., Rechtsgüterschutz und Schutz der Gesellschaft, 1972.

7 Confr. VOn Feuerbach, P. J. A., Lehrbuch des gemeinen in Deutschland gültigen peinlichen Rrechts -14a edición-, por MitTermeier K. J. A., $\$ 23$.

${ }^{8}$ Hobbes, T. Leviathan, 1651, Capítulo 14.

9 FICHTE J. G., Das System der Rechtslehre, 1812, citado según la edición de los Ausgewählte politische Schriften, editados por BATSCHA Z. y SAAGE R., 1977, pp. 217 y ss. [316].

10 Grotius, De iure Belli ac Pacis, 1625, p. 49; Hobbes, Leviathan, 1651, Capítulo 28. La distinción entre pena y venganza tiene su razón de ser, muy probablemente, en la filosofía de la pena del cristianismo. El punto de partida es el Sermón de la Montaña (Lucas, 6,27; Mateo, 5, 43) en el que se predica un nuevo significado a la aforismo bíblico "ojo por ojo, diente por diente". En el Evangelio se entiende que el amor al prójimo no tiene límites frente a nuestros enemigos. El entendimiento de esta prédica se manifiesta en la práctica en esta distinción entre pena y venganza. Lo que habría querido
} 
fundamento de esta moderna ideología penal provenía del derecho de la guerra. Hugo Grotius explicaba en el capítulo XX de su famoso De iure Belli Ac Pacis (1625) que "en la consideración de las causas que puedan dar comienzo a una guerra hemos dicho que son la reparación del daño o la pena"11. El fundamento de la pena, decía Grotius, es la razón de la naturaleza misma de las cosas: "Contradice la naturaleza de los hombres que se relacionan con otros hombres para satisfacerse con el dolor ajeno como tal. Cuanto menos poder racional tiene el hombre, tanto más tiende a la venganza" ${ }^{12}$. Probablemente esta es la razón por la cual la respuesta penal ha sido asumida en forma monopólica por el Estado, convirtiendo al derecho penal en derecho público, en el que la relación jurídica se establece entre el Estado y el delincuente. A diferencia del derecho medieval, la víctima solo tenía en el marco del conflicto penal un papel procesal limitado a la reparación del daño causado por el delito.

"Pienso -agregaba Grotius- que la pena debe contemplar la utilidad del que ha pecado o de aquel cuyo interés es que no se peque, o de algún otro"13. Y concluía: "El fin, de que el lesionado no sufra nuevamente lo mismo, puede ser alcanzado de tres maneras: primera, excluyendo al delincuente; luego quitándole la fuerza que le permite lesionar; finalmente, enseñándole, mediante la aplicación de un mal, que no debe pecar (...). Para que otros no repitan la lesión la pena debe ser pública y visible; entonces se podrá tomar ejemplo de ella" 14 .

Esta ideología de la pena y del derecho penal culminó con la teoría de la coacción psicológica de Feuerbach, que procuró definir con más precisión el fin de la pena "evidentemente necesaria”. La pena, según Feuerbach, sería legítima si era el medio para garantizar la situación jurídica cuya existencia es el fin del Estado. "Las lesiones jurídicas de toda clase contradicen esta finalidad del Estado y es necesario, por ello, que en el Estado no tengan lugar lesiones de derechos. El Estado está autorizado y obligado a encontrar las instituciones que hagan imposible en general las lesiones de derechos"15. Por lo tanto: "La pena civil (poena forensis) es el mal amenazado por el Estado mediante una ley y aplicado según ella" (...) "El fin de la amenaza de la pena es la intimidación de todos; el fin de la acción de infligirla es la eficacia de la amenaza legal, pues sin ella dicha amenaza se convertiría en vacía (ineficaz)"16.

excluir el Sermón de la Montaña es la venganza. De todos modos, el deber hacia los enemigos, que estaba ya en el Antiguo Testamento (Éxodo, 23; en otro sentido: Ester, 9; menos claro en Job, 16), no tuviera allí un sentido tan claro. En el derecho eclesiástico, sin embargo, distinguió poenae medicinalis y poenae vindicativae. La primera tenía la finalidad de curar el alma del pecador. La segunda servía para la expulsión de la Iglesia del miembro infectado (confr. VON BAR C. L. Geschichte des deutschen Strafrechts und der Strafrechtstheorien, 1882, pp. 82 y ste.).

${ }^{11}$ Ibidem, p. 39.

12 Grotius. De iure Belli ac Pacis, 1625, p. 49.

13 Ibidem, p. 51.

${ }^{14}$ Grotius, op. cit. (n. 12),. pp. 53 y ss.

${ }^{15}$ Feuerbach P. J. A. Lehrbuch des gemeinen in Deutschland gültigen peinlichen Rechts -14. edición- 1847, pags. 36 y 37.

${ }^{16}$ Ibidem, p. 39. En forma similar FICHTE J. G., op. cit. (n. 9), pp. 320 y ss. 
La capacidad legitimante de la finalidad preventiva, es decir, lo que hasta entonces permitía diferenciar la pena de la venganza, fue puesta en tela de juicio a fines del siglo XVIII. El idealismo alemán se diferencia del iluminismo en que la diferencia entre pena y venganza debe ser consecuencia de la dignidad de la persona: la persona es un fin en si misma y no puede ser un medio para alcanzar otros fines. En este contexto toda finalidad preventiva carece de legitimidad. Dicho de otra manera: cambia la manera en la que el autor del delito debe ser tratado por la sociedad. La dignidad de la persona debe operar como un límite a la fundamentación del derecho penal en la razón instrumental. Por lo tanto, lo que justifica la pena, es decir la reducción de la libertad, es la justicia de la misma, su proporcionalidad con el mal causado por el delito. Con otras palabras: su proporcionalidad con la culpabilidad del autor: "El efecto jurídico de la culpabilidad -decía Kant- es la pena $($ poena $) " 17$.

Esto quiere decir que no todo medio adecuado para impedir el delito puede ser por ello legítimo. El límite del ius puniendi, por lo tanto, no debe ser la utilidad de la pena para alguien, sino la justicia. Esta nueva concepción había sido esbozada por primera vez por Kleinschrod en 1794 al cuestionar que la intimidación, en el sentido de Feuerbach, pudiera ser el fin principal de la pena. "El castigo de un hecho -adelantó entonces Kleinschrod- se determina por su gravedad y su moralidad". "No es pensable ningún derecho de castigar a una persona -concretó- a causa de todos los delitos posibles de otro, ni de usar a la persona, que es un fin en sí mismo, como medio para un fin que le es ajeno" 18 .

Pero, a partir de aquí, lo cierto es que el derecho penal de origen liberal se preocupó de la legalidad, pero salvo en lo referente a la abolición de la tortura, tuvo, como se verá enseguida, poca consideración por el principio de la humanidad de las penas, que necesitó más de un siglo para ingresar en el catálogo de los principios del derecho penal ${ }^{19}$.

La idea entrevista por Kleinschrod fue plasmada en toda su dimensión poco después por Kant: "La pena judicial (poena forensis), [...] distinta de la natural (poena naturalis), no puede nunca ser impuesta como medio de favorecer bienes de otro, del delincuente mismo o de la sociedad, sino que tiene que serle impuesta porque él ha delinquido; pues la persona nunca puede ser manipulada por las intenciones de otro ni mezclada con los objetos de los derechos reales, contra el cual se protege su innata personalidad, aunque pueda ser condenado a sufrir una pena civil”" 20 .

"La ley penal -continuaba Kant- es un imperativo categórico"; de lo contrario "un tribunal se convertiría en un cuerpo médico colegiado" y lo sería, además, "con desprecio rechazable, pues la justicia deja de ser tal cuando se renuncia a ella por algún precio" ${ }^{21}$. El

\footnotetext{
${ }^{17}$ KANT I. Die Metaphisyk der Sitten -2a ed.- 1798, pp. 29 y s.

18 Kleinschrod G. A. Grundbegriffe und Grundwahrheiten des peinlichen Rechts, 1794, pp. 113 y s. Kleinschrod admitía, sin embargo, que la pena "no puede tener otro fin que evitar delitos futuros" (p. 102).

${ }^{19}$ Confr. Jescheck H.-H. /Th. Weigend. Lehrbuch des Strafrechts, AT -5a edición-, 1996, pp. 27 y ss.

${ }^{20}$ Kant I. Die Metaphysik der Sitten, 1797, p. 197.

${ }^{21}$ Ibidem.
} 
principio de justicia pública, por lo tanto, no puede ser otro que la igualdad entre el daño causado y mal sufrido como consecuencia, lo que significa que "solo el derecho retributivo (el ius talionis) [...] puede determinar la cantidad y la cualidad de la pena". Cualquier otro principio sería inadecuado a la "pura y estricta justicia" 22 . El criterio de la legitimidad de la pena, ya no es su finalidad, sino la justicia irrenunciable de la retribución equivalente al mal causado.

La idea de justicia y de persona como fin en sí mismo, sin embargo, no impedían a Kant mantener las conclusiones drásticas ya defendidas por Rousseau ${ }^{23}$ respecto de la exclusión del delincuente del Estado. Rousseau pensaba en tal sentido que "todo malhechor que ataque al derecho social deviene por su deserción rebelde y traidor a la patria” (...) tal enemigo no es una persona moral, es un hombre y el derecho de la guerra concede matar al vencido". Y Kant sostenía en esa línea que "Aquellas infracciones de la ley pública que hacen al que las comete incapaz de ser ciudadano del Estado, se denominan simplemente crimen" 24 . También coincidían en relación a la pena de muerte, y en la consideración del penado como un esclavo 25 .

Hegel avanzó más todavía en el famoso $\$ 100$ de sus Grundlinien der Philosophie des Rechts, de 1821. El Estado debe hacer valer no solo el concepto de delito, sino la "racionalidad formal". De ello se deduce, a mi entender, que si la acción expresa la voluntad del delincuente, este será honrado como un ser racional con la pena que es su propio derecho, dado que ella está ya contenida en dicha voluntad: él quiere sabiendo que lo querido acarrea la pena; él decide merecer la pena por su acción. Por tal razón, este honor solo puede brindársele si "el concepto y la medida de su pena se refieren a su hecho". De lo contrario sería tratado como un animal dañino que es necesario convertir en inocuo. Tampoco se honraría al delincuente si la pena se aplicara con el fin de intimidar o de educar al delincuente. En suma: también Hegel rechazó expresamente la idea de Feuerbach pues entendía que la pena como amenaza desconocía al ser humano libre y que esto excluía su juricidad, en la medida en la que esa tesis postulaba algo que, según Hegel, no era diferenciable de la acción de "levantar un bastón frente a un perro" (última adición al $\$ 99)$.

Respecto de la teoría de la pena de Feuerbach, en consecuencia, la teoría absoluta representada por Kant y Hegel era fuertemente limitativa. El legislador estaba vinculado por el imperativo de justicia y ello le impedía imponer al autor del delito, como pena, un mal superior al mal causado, aunque fuera preventivamente necesario. Las finalidades preventivas de la pena, que habían cumplido su función para diferenciar la pena de la venganza, cuya falta de límites Kleinschrod ya objetaba a la tesis de Feuerbach ${ }^{26}$, se tornaban ahora ilegítimas limitaciones de la libertad.

\footnotetext{
22 Ibidem, p. 198. Sin embargo, Kant consideraba dudoso que merecieran la pena de muerte el infanticidio y el duelo, p. 204.

${ }^{23}$ Confr. Rousseau J. J. Du contract social, 1762, L. II, Cap. V: (citado según la Mairet Gérard, Le Livre de Poche, 1996, p. 69). Ver el comentario al respecto de Pérez del VAlle C. en CPCr 75 (2001), pp. 597 y ss.

${ }^{24}$ KANT I, op. cit. (n. 20), p. 196.

25 Ibidem, p. 199.

${ }^{26}$ Loc. cit. p. 112.
} 
El derecho penal de la primera mitad del siglo XIX, por lo tanto, se basaba en una clara distinción entre pena, por un lado, y seguridad o defensa de la sociedad ante el peligro de futuros delitos, por otro. El derecho penal debía limitar la libertad solo en la medida del mal causado por el autor, su dirección temporal debía ser el pasado, no la prevención de futuros delitos. La defensa anticipada de la sociedad quedaba fuera de la legítima función del derecho penal. Ejemplo: Feuerbach al comienzo de su Revisión de los Conceptos Fundamentales del Derecho Penal en 1799, antes de formular su teoría de prevención general, expuso una premisa importante: "la pena se diferencia de la seguridad y la defensa" 27 . La función del derecho penal, en suma, debía ser distinta de la función policial de prevención ${ }^{28}$.

Precisamente esta premisa ideológica del derecho penal fue cuestionada por los positivistas en la segunda mitad del siglo XIX. La consigna principal del Marburger Universitätsprogramm de Franz v. Liszt, de 1882, no ofrecía duda alguna: "Nosotros queremos dejar totalmente de lado la pena retributiva" [...] "La idea de fin, que hasta ahora nos ha guiado feliz y seguramente, tiene que continuar siendo nuestra conductora. Nuestra concepción de la pena como protección de bienes jurídicos requiere ineludiblemente que en el caso particular se imponga aquella pena (por contenido y extensión) que sea necesaria para la protección del mundo de los bienes jurídicos mediante ella. La pena correcta, es decir la pena justa es la pena necesaria" ${ }^{29}$. Detrás de este programa se encuentra la negación de la libertad del individuo y su reemplazo por la concepción determinista.

A partir de aquí se postuló una nueva dirección temporal hacia el futuro, es decir un derecho basado en la prevención. La idea no era nueva. Lo nuevo era la adaptación de la prevención a las necesidades determinadas por las distintas especies de delincuentes empíricamente constatadas. El derecho penal no debe tratar de la misma manera al delincuente ocasional, al susceptible de ser reeducado o al imposible de ser reeducado. Dicho de otra manera: el Estado estaría legitimado para limitar la libertad cuando ello sea necesario para impedir delitos futuros según la especie criminológica del autor. De esta manera la necesidad (metafísica) derivada del imperativo de justicia era reemplazada por la necesidad (política) impuesta por la defensa de la sociedad ante el delincuente peligroso. El discurso de la exclusión del delincuente del Estado de Rousseau (por no ser persona moral) y de Kant (por ser incapaz de ser ciudadano del Estado) persistió, pero con ropaje empírico.

"La pena -decía $v$. Liszt- alcanza su fuerza total y propia en la ratificación de la voluntad del orden jurídico y en la ejecución penal mediante la coacción punitiva” (...). Liszt llegó, inclusive, a la conclusión de que "la función de la pena también puede llegar a la sustracción al delincuente inútil para la sociedad de su posibilidad física de comisión de nuevos delitos separándolo de la sociedad, en forma temporal o definitiva (selección artificial). Aquí hablamos de hacer inocuo al delincuente" 30 . "La sociedad tiene que protegerse

\footnotetext{
${ }^{27}$ Revisión del Grundsätze und Grundbegriffe des positiven peinlichen Rechts, 1, 1799, p. 19.

${ }^{28}$ FeUerbach P. J. A. op. cit. (n. 15), pp. 704 y ss.

29 Strafrechtliche Vorträge und Aufsätze, I 1905, pp. 160 y s.

30 1921, p. 7. La idea de inocuización se encuentra ya en KLEINSCHROD, op. cit. (n. 18). p. 103, pensaba que la sociedad podía hacer inocuo a un delincuente tanto física como moralmente.
} 
del irrecuperable; y dado que no queremos decapitarlo ni colgarlo y que deportarlo no podemos, solo nos queda el encierro perpetuo (o por tiempo indeterminado)"31. La reclusión perpetua, en fin, resultó entonces un sustituto de la pena de muerte.

Estas ideas de $v$. Liszt han sido la base de la revisión del derecho penal clásico incorporando a la función del derecho penal la defensa de la sociedad, otorgándole al Estado una función paralela a selección natural de Darwin ${ }^{32}$ que le permitía llevar a cabo una selección artificial respecto de la especie humana, con la correspondiente reducción de la libertad que ello significaba. De una u otra forma, esta ideología inspiró a la segunda generación de reformas de los códigos penales europeos, cuyo modelo fueron los proyectos y códigos penales italiano de 1930 y suizo entrado en vigor en 1937, que previeron para los delincuentes habituales medidas de segregación no limitadas por la gravedad de la culpabilidad.

De esta manera, las consecuencias jurídicas limitadoras de la libertad ya no se justificaban solo frente al autor culpable y en la medida de su culpabilidad por el delito cometido. Se postuló una extensión del derecho penal a la prevención frente al peligroso, continuando de esa manera el discurso de la segregación de fines del XVIII. El derecho penal se convirtió en un derecho penal de defensa social, es decir un derecho penal que, si fuera necesario, estará legitimado para utilizar la persona del autor como medio para mantener la seguridad de la sociedad. Consecuentemente, la idea moral de persona desarrollada por el idealismo alemán fue seriamente relativizada a partir del "descubrimiento" de la peligrosidad. Decía Aschaffenburg, criticando lo que a su juicio era la paradoja del derecho penal del siglo XIX: "Un perro que muerde debe estar atado con una cadena; ¡desgraciado del amo que no cumpla con ello! Pero a un hombre peligroso para la sociedad se le deja libre con permiso del Estado"33. Esta es exactamente la comparación de la persona con el animal que censuraba Hegel.

El discurso defensista asumió, al menos dos formas. Por un lado se pensó que ante el delito la sociedad tenía el derecho de segregar al autor por el tiempo necesario para protegerse: en esta afirmación se generó la llamada "sentencia indeterminada" que Jiménez de Asúa definía en su tesis doctoral en 1913 como "el sistema por el cual se somete a una persona al régimen penal exactamente como un enfermo es enviado a un hospital hasta que su curación sea absolutamente completa" ${ }^{\text {"2 }}$. Así se convertía a los tribunales en los cuerpos colegiados de médicos censurados por Kant.

La propuesta de este discurso de segregación, receptada en las reformas legislativas de la primera mitad del siglo XX es la expresada en el llamado derecho penal de doble vía, que, junto a la pena por la culpabilidad, prevé también medidas de seguridad contra el autor peligroso (por enfermedad mental o por su demostrada tendencia a la reincidencia), aplicables incluso acumulativamente. De esta manera la posibilidad de limitación de la libertad se amplió considerablemente. "Medidas de seguridad -definía v. Liszt- son medidas estatales mediante las que se procura la adaptación del individuo a la sociedad (medidas educativas y

${ }^{31}$ Der Zweckgedanke im Strafrecht, 1882, citado según Strafrechtliche Vortäge und Aufsätze, I 1905, pp. 126 y ss. [169].

32 On the Origin of Species by Means of Natural Selection, 1855.

33 Das Verbrechen und seine Bekämpfung, 1906, p. 265.

34 JimÉnEZ DE ASÚA, L. La sentencia indeterminada, 1913, p. 62. 
de mejoramiento) o la segregación de la sociedad de los incapaces de adaptación”35. Estas medidas deben reemplazar la pena, cuando el autor es incapaz de culpabilidad, o completarla, cuando la pena es insuficiente para los que, después de cumplida la misma, manifiestan la peligrosidad propia de la habitualidad. El medio propuesto a estos efectos fue la medida de seguridad caracterizada con diversas denominaciones tales como internamiento en casa de trabajo, en granjas agrícolas o más modernamente custodia de seguridad.

Los proyectos alemanes contemplaron a partir del de 1919 esta custodia de seguridad aplicable después del cumplimiento de la pena. Inicialmente se la previó con una duración de hasta cinco años; actualmente el Código penal alemán ha extendido su duración hasta 10 años. Los Proyectos austriaco, suizo, danés, sueco y argentino posteriores a la Primera Guerra Mundial adoptaban medidas semejantes ${ }^{36}$. Desde su creación las medidas de seguridad han tenido un campo común con las penas: "Ambos institutos jurídicos -explicaba $v$. Liszt ${ }^{37}$ - se relacionan como círculos secantes: la pena puramente intimidante (pena retributiva) y la pura medida de seguridad se oponen una a la otra; pero, dentro de su campo común, la medida de seguridad puede reemplazar a la pena (operar con ella vicarialmente) y viceversa”.

Es necesario subrayar que las medidas de seguridad no se limitan a las aplicables a los declarados exentos de responsabilidad (p. e.: incapaces de culpabilidad), como erróneamente pensó el legislador español en 1995, sino que también pueden alcanzar a personas responsables que manifiestan serios riesgos de reincidencia. La incomprensión del legislador español de 1995 lo llevó a una rara mezcla de las relaciones de la pena y la seguridad frente a reincidentes y habituales, previendo para estos un aumento de la pena, con fines puramente aseguradores, difícilmente compatible con el derecho penal de culpabilidad ${ }^{38}$.

La legitimación de la reacción penal en la necesidad defensiva condujo consecuentemente también a nuevas instituciones como la condena de ejecución condicional, para las penas cortas privativas de la libertad, o la libertad condicional, que eran la consecuencia lógica de la inutilidad de la ejecución cuando ella se mostrara innecesaria.

Pero la ideología de la dirección del derecho penal hacia el futuro, es decir preventivo, permitía, de todas maneras, serias limitaciones de la libertad, sobre todo en la franja de la estadística criminal en la que se registra la criminalidad de gravedad media y en la que probablemente se dan los casos de reincidencia estadísticamente más significativos. En la medida en la que lo necesario era también lo legítimo, la distinción conceptual entre penas y medidas perdió claridad.

5.

Después de la Segunda Guerra Mundial la oposición a la filosofía penal del positivismo dio lugar a una importante revisión de la ideología penal y la política criminal en ella inspirada. Las experiencias vividas convirtieron a la dignidad de la persona y al derecho

\footnotetext{
${ }^{35}$ Loc. cit. p. 246.

36 Confr. GRISPIGNi F. Il nuovo Diritto Criminale negli avamprogetti della Svizzera, Germania ed Austria, 1911.

${ }^{37}$ Lehrbuch, citado, p. 247

${ }^{38}$ No obstante ver STC 150/1991.
} 
al libre desarrollo de la personalidad en el centro de los valores fundamentales del Estado (Constitución italiana de 1948, art. 2; Ley Fundamental alemana de 1949, arts. 1 y 2; Constitución española, art. 10; Constitución griega, art. 5).

Las consecuencias de las ideas de segregación y de selección artificial inspiradoras de las medidas de seguridad fueron entonces considerablemente reducidas. Los medios a través de los cuales se operó esta reducción fueron: el fortalecimiento del principio de culpabilidad en el ámbito de las penas, la introducción del principio de proporcionalidad para las medidas de seguridad y, sobre todo, de la idea de resocialización en lo concerniente a la ejecución de penas y medidas, que en España llegó a ser incorporada al catálogo de derechos fundamentales (art. 25. $2 \mathrm{CE}^{39}$ ).

Sin embargo, el programa político criminal del Proyecto Alternativo alemán de 1966, que acentuó estos puntos de vista, no prescindió ni de la pena perpetua de privación de la libertad, ni de la custodia de seguridad, aunque subrayó fuertemente los aspectos de terapia social de una ejecución basada en el tratamiento. En la práctica el programa de la resocialización determinó que tanto la reclusión perpetua como la custodia de seguridad, dejaran de ser definitivamente excluyentes, dado que debían permitir que el condenado pudiera, en sucesivas revisiones de su situación, reintegrarse a la vida libre en la sociedad y que su ejecución contemplara acentuadamente aspectos de terapia social ${ }^{40}$.

6.

El programa político del derecho penal de la resocialización, formulado hace casi medio siglo, condiciona su legitimación a la comprobación empírica de la realización de sus expectativas. Pero, esta comprobación no ha sido nunca lograda satisfactoriamente. Como dice Hassemer, "la búsqueda de una solución concluye en un no-saber. No solo la teoría de la prevención individual es deudora de una respuesta a la pregunta por sus efectos; tampoco la teoría de la prevención general reformulada puede ofrecer datos sobre la medida en la que actúan la amenaza penal y la ejecución penal como modelo del control social. Las teorías preventivas se reducen a una esperanza de solución, no más" ${ }^{41}$. Sin perjuicio de la falta de comprobación empírica, el programa fue sometido a otras objeciones ideológicas que denunciaban la ausencia de un derecho de la sociedad para imponer coactivamente un tratamiento de adaptación a sus valores.

La reacción frente a una fracasada legitimación del derecho penal en conocimientos empíricos de las ciencias sociales, fue la renuncia a la legitimación del derecho penal como instrumento de prevención especial. En lugar de la legitimación basada en la razón instrumental, se propone legitimar el derecho penal por medio de la razón comunicativa ${ }^{42}$.

\footnotetext{
${ }^{39}$ El Tribunal Constitucional ha eliminado en la práctica este derecho fundamental con dudosos argumentos.

${ }^{40}$ En Francia y en Holanda se dieron corrientes de pensamiento similares: en Francia ver ANCEL, M. La Défense Sociale, 1985, con un programa poco claro de reformas del derecho penal. En Holanda ver: La Criminologie et la Philosophie pénal de l'école d'Utrecht, de varios autores y con prefacio de LÉAUTÉ J. 1977.

41 Einführung in die Grundlagen des Strafrechts, 1981, p. 298.

42 Bacigalupo E. en GómeZ-Jara Díez C. (Ed.), Teoría de sistema y Derecho Penal, 2005, pp. 319 y ss.
} 
Desde esta perspectiva la legitimidad de la pena reside en su función de comunicar socialmente la desaprobación de la norma violada por el autor y, de esta forma, ratificar y estabilizar las expectativas normativamente garantizadas. "La pena es la demostración de la validez de la norma a costa del responsable. De ello se desprende un mal, pero no ha cumplido su función con este efecto, sino solo a través de la estabilización de la norma vulnerada" 43 . Este concepto no excluye una ejecución penal basada en el tratamiento ni la humanización del mismo.

La idea de que el derecho penal solo tiene la función de ratificar la vigencia de la norma vulnerada y de desautorizar la conducta que vulneró la norma conduce necesariamente a plantear autónomamente la cuestión de la justificación del mal que, en todo caso, es consustancial con la pena. Dos preguntas surgen de inmediato: ¿Podría el derecho penal cumplir su función solo mediante la expresión de la desaprobación del hecho, sin aplicar un mal al autor? ¿Cómo se justifica que el Estado, además de desaprobar el hecho, esté autorizado a infligir ese mal? Cabría pensar que la ratificación de la norma puede ser lograda con la simple declaración pública de desaprobación de la conducta por parte del Estado. En estos casos la aplicación del mal sería superflua y se debería renunciar a ella ${ }^{44}$, o sería suficiente con una reserva de pena ${ }^{45}$ o con aplicar una pena leve siempre y cuando ello no signifique bagatelizar el bien jurídico lesionado ${ }^{46}$. Tomada en un sentido estricto, por lo tanto, la teoría de la prevención general positiva debería conducir a una notable limitación del derecho penal actual. Si no se sabe para qué sirve el mal que actualmente acompaña al reproche, su necesidad devendría problemática. Pero la cuestión no es tan simple. Diversos autores piensan que, de todos modos, el mal de la pena, entendido como pérdida de derechos, es necesario para que la ratificación de la norma sea realmente eficaz $(J a k o b s)^{47}$, o porque el autor no solo ha vulnerado el orden jurídico, sino también privado a otro de un bien importante, lo que requiere un respuesta basada en el principio de justicia $(K \ddot{u} h l)^{48}$, o porque es suficiente con esperar una contribución positiva a la prevención general (A. v. Hirsch) ${ }^{49}$.

Este es el estado de la discusión actual. Es posible suponer estemos próximos a entrar en una fase crítica en la que la ciencia penal y la opinión pública se opongan manifiestamente. Hoy parece que el público está más inclinado hacia la venganza y poco preocupado por el principio de proporcionalidad. Habrá seguramente dificultades para descubrir un punto de encuentro basado en la razón. Esto se percibe actualmente en la tendencia al populismo y al oportunismo ${ }^{50}$ de la legislación penal que alientan cotidianamente los medios de comunicación y que los Parlamentos adoptan con frecuencia.

\footnotetext{
43 JAKOBS G. Strafrecht -2a edición- 1991, p. 6.

${ }^{44}$ GÜNTHER K. Fest. f. Lüderssen, 2002, pp. 205, 215.

45 Hassemer W. Fest. f. Spinellis, pp. 399 y ss.

46 Streng, Mschr Krim, 2004, pp. 127 y ss.

47 JaKовS, G. Die staatliche Strafe: Bedeutung und Zweck, 2004, p. 30; similar W. Frisch, en festskift till Nils Jareborg, 2002, pp. 207 y ss.

48 KÜHL K. en Fest. f. A. Eser, 2005, p. 160.

49 V. HIRSCH A. Fairness, Verbrechen und Strafe: Strafrechtstheoretische Abhandlungen, 2005, p. 37.

50 PritTwitz C., en Cocco G., Interpretazione e precedente giudiziale in diritto penale, 2005, pp. 81 y ss.
} 
En cualquier caso es conveniente señalar que la capacidad preventiva del derecho penal es reducida. El problema de la seguridad y el de la pena se han desarrollado tradicionalmente de manera separada: la prevención requerida por la seguridad pública solo es cumplida por el derecho penal en una medida menor. La prevención más eficaz es la policial cumplida en el marco de las garantías del Estado de Derecho. Es totalmente equivocado creer que la amenaza legal de penas drásticas puede por sí sola resolver el problema de la seguridad pública.

Para concluir permítaseme un ex cursus. Últimamente las discusiones sobre la ideología del derecho penal han girado en torno al llamado "derecho penal del enemigo" en la versión que del mismo ha elaborado Günther Jakobs. No he de reproducir aquí los términos de la polémica, referida a dos palabras: "enemigo" y "persona”. Me limitaré a algunas consideraciones sobre ella ${ }^{51}$.

La cuestión es en lo conceptual antigua. Kant y Hegel entendieron que un derecho penal dotado de funciones preventivas afectaba decididamente la dignidad de la persona, pues implicaba su tratamiento como cosas, es decir como objetos materiales ${ }^{52}$.

La tesis de Jakobs proviene de esta tradición de pensamiento. Se basa, en primer lugar, en distinguir entre sancionar para ratificar la norma vulnerada por el culpable, que considera la función genuina del derecho penal, y el tratamiento del delincuente, como fuente de peligro para el modelo orientador de conducta que es la norma. Esta debe ser una función propia del derecho de policía que "ensucia el derecho penal" 53 actual. En segundo lugar, Jakobs deduce de esta configuración del sistema penal vigente que el derecho penal solo trata al sujeto como persona, es decir como alguien a quien se reconoce la plenitud de sus derechos, cuando es posible enrostrarle su culpabilidad. Cuando el derecho trata al sujeto como fuente de peligro, por el contrario, no lo trata como persona.

Esta conclusión, conviene aclarar, no es el fundamento de un programa de política criminal; debe ser entendida como una descripción del derecho vigente. Jakobs explica, a partir de esta distinción, que un derecho penal, como el actual, que tiene instituciones como la custodia de seguridad, que adelanta la punibilidad a las asociaciones ilícitas como tales, que prevé en su procedimiento penal la incomunicación, las intervenciones telefónicas y otras formas de injerencia en la intimidad para prevenir la comisión de delitos, que emplea en la investigación agentes encubiertos, que utiliza la prisión provisional en casos

\footnotetext{
51 Conviene advertir que la expresión "derecho penal del enemigo" difícilmente puede ser relacionada con la posición sostenida por Carl Schmitt en su monografía Der Begriff des Politischen, 1932, 5a reedición de la de versión de 1963, en la que dice: "También el enemigo tiene un status; no es un delincuente" (prólogo de 1963, p. 11) y "el enemigo político no es necesariamente malvado ni estéticamente feo (...) El es sencillamente el otro, un extraño, (...) de tal manera que en un caso extremo es posible un conflicto con él" (texto de 1932, p. 27).

52 En este punto me parece que se equivoca L. Gracia Martín, Homenaje a R. Morurullo, 2005, p. 447 [488] cuando sitúa la cuestión en el concepto de persona de Kant. La cuestión se refiere al tratamiento que requiere una persona (de carne y hueso) por parte del Estado.

53 JAKOBS, G. en ZStW 117 [2005], 840.
} 
de alarma social, etc. no trata al sujeto como una persona, sino como una fuente de peligros, con una fuerte reducción de sus derechos procesales y de la presunción de inocencia y, consecuentemente, como un enemigo, por lo que, en ese caso no podría ser un Estado de Derecho pleno ${ }^{54}$.

Hasta aquí, la descripción. En tanto el derecho penal del enemigo no sea la recomendación de un programa para el tratamiento de sujetos como fuente de peligro, como el llamado "crime control model" de Herbert L. Packer"s, puede servir también como una denuncia principista de las extralimitaciones penales y procesales vigentes de nuestro Estado de Derecho. Jakobs explica que "cuando se habla del derecho penal del enemigo no se quiere significar al mismo tiempo 'procesos sumarios', ni 'penas por sospecha', ni 'descuartizamiento público para intimidar' [al público] o procedimientos similares” 56 . Podemos agregar: cuando se habla de derecho penal del enemigo se habla de instituciones del derecho vigente hoy.

A partir de aquí la valoración. La posibilidad de diferenciar conceptualmente entre personas y fuentes humanas de peligro que carecen de ciertos derechos (sobre todo procesales) garantizados por la Constitución, es en realidad un problema de definición. La definición de "persona" no es un problema nuevo en la ciencia jurídica ni el concepto de persona es único ${ }^{57}$. Pero la tesis especialmente polémica en la tesis de Jakobs, difícil de compartir, es la que sostiene que el status de persona se puede perder por comportamientos que de alguna manera no garantizan fidelidad al derecho y que esa pérdida excluye la pretensión de ser tratado como persona ${ }^{58}$. A ello se opone la afirmación de que el status de persona es intangible y no depende de la adecuación del individuo a la expectativas de la sociedad ${ }^{59}$. Ambos son puntos de vista últimos, no demostrables.

Me parece preferible otro planteamiento de la cuestión: hasta qué punto el Estado de Derecho puede invocar, como fundamento de las medidas penales de neutralización de sujetos peligrosos, sus propios derechos de necesidad para limitar de manera radical derechos fundamentales. La discusión, como todos comprenderán, se desarrolla en un contexto histórico de la mayor complejidad. La caracterización que de ella hace Ulrich Beck es impactante: "El atentado terrorista suicida ha borrado, en general, los límites de las distinciones que sostienen nuestra imagen del mundo: en particular entre la guerra y la paz, entre lo militar y lo policial, entre la seguridad interior y la seguridad exterior" 60 . Es difícil que este contexto histórico la cuestión del terrorismo no influya en la discusión. Hay quienes piensan que en consecuencia las cuestiones del derecho penal del enemigo exceden el marco del derecho penal y que, a la luz de los acontecimientos, se refieren, en realidad,

\footnotetext{
54 Sobre el nivel de garantías del Estado de Derecho entendido sin ninguna renuncia: M. Jahn, Das Strafrecht des Staatsnotstandes, 2004. Ver la recensión de JAKOBS, G. ZStW 117 [2005], pp. 418 y ss.

55 "Two Models of the Criminal Process", en 113 U. Penn. Law Review. 1, 1964.

56 ZStW 117 [2005], 846.

57 Kelsen H. Reine Rechtslehre, 2a edición 1960, pp. 176 y ss., ya demostró convincentemente que la llamada "persona natural", en tanto portador de derechos y deberes (ver C. Civil, art. 29 y ss.) es una construcción jurídica tan "artificial”, como la de las personas jurídicas. Ver también: PARMA C., El pensamiento de G. Jakobs, 2a reimpresión, 2004, pp. 55 y ss. 58 ZStW 117 (2005), p. 843.

59 Confr. KunZ K.- L., en Fest. f. Albin Eser, 2005, pp. 1375 y ss.

${ }^{60}$ Das Schweigen der Wörter; über Terror und Krieg, 2002; ver también: PAWLIK M., Der Terrorist und sein Recht, 2008.
} 
a una problemática del derecho de la guerra, que debe ser tratada con otros criterios jurídicos, aunque dentro de los límites constitucionales ${ }^{61}$.

La discusión está abierta. Por un lado se sostiene que la invocación de los principios de la necesidad no están a disposición del Estado y que una defensa de la seguridad basada en el estado de necesidad no es legítima ${ }^{62}$. Por otro lado, se afirma que las medidas del llamado derecho penal del enemigo deben ser "limitadas a lo necesario", pero que "la renuncia a tales instrumentos puede vaciar el derecho de los ciudadanos a su seguridad" 63 , reconociendo, al mismo tiempo, que "el problema de los límites no tiene aun solución" 64 . Sin embargo es claro, quiero subrayar, que no todo está justificado. Creo con Ronald Dworking que "la metáfora del equilibrio entre derechos y seguridad es engañosa" y "no debemos suponer que cualquier acto que mejore nuestra seguridad, aunque lo sea en muy pequeña medida, queda por esa razón automáticamente justificado" 65 .

Este es el problema ideológico real de nuestro tiempo. Solo puedo plantearlo; no tengo la solución definitiva: ¿hasta dónde puede intervenir el Estado mediante el derecho penal, si es que está autorizado a hacerlo, para garantizar la seguridad colectiva? Es recomendable no enturbiarlo con una simple discusión de palabras. Debemos pensar en serio cómo debemos tratar a una persona y bajo qué condiciones es legítimo restringir sus derechos por ser considerado como una fuente de peligros.

\footnotetext{
${ }^{61}$ Confr. M. Pawlik M, op. cit. (n. 60).

62 JAHN M, op. cit. (n. 54).

63 JAKOBS, G. en ZStW 117 [2005], p. 847.

${ }^{64}$ Ibidem, p. 846.

65 Is democrcy possible here?, 2006 (citado según la traducción de E. Weikert García con el título "La democracia posible", 2008, p. 70.
} 